\title{
Effect of accelerated environmental aging on tensile properties of oil palm/jute hybrid composites
}

\begin{abstract}
Recently natural fibre based hybrid composites are receiving growing consideration due to environmental and biodegradability properties. In order to look behaviour of hybrid composites in outdoor applications, its environmental degradation properties such as UV accelerated weathering properties need to analyze. In this study oil palm empty fruit bunch (EFB) and jute fibres reinforced hybrid composites, pure EFB, pure jute and epoxy composites were fabricated through hand lay-up techniques. Hybrid composites with different layering pattern (EFB/jute/EFB and Jute/EFB/jute) while maintaining $40 \mathrm{wt}$ \% total fibre loading were fabricates to compared with EFB and jute composites. Effect of UV accelerated environmental aging on tensile properties of epoxy, pure EFB, pure jute, and hybrid composites were assessed and evaluate under UV exposure. Tensile samples of all composites were subjected to accelerated weathering for $100 \mathrm{~h}$, at temperature $\left(75^{\circ} \mathrm{C}\right)$, relative humidity (35\%), Light (125 W/m2), and water spray off. Obtained results indicated that there is reduction in tensile strength, modulus and elongation at break values of hybrid and pure composites due to degradation of lignin and fibreï matrix interfacial bonding.
\end{abstract}

Keyword: UV radiation; Water spraying; Tensile properties; Hybrid composites; Environmental aging 